\title{
Phytochemical Investigation on Stem of Calotropis Procera (Ait.) R.Br. (Asclepiadaceae)
}

\author{
Konathala Rajesh $^{1}$, S.P.Preethi Priyadharshni ${ }^{2}$, K.Eswar Kumar ${ }^{2}$, \\ T.Satyanarayana ${ }^{2}$. \\ ${ }^{l}$ Pharmacology Dept, College of Medicine and Health, Adigrat University, Adigrat, Ethiopia. \\ ${ }^{2}$ University College of Pharmaceutical Sciences, Andhra University, Visakhapatnam, India.
}

\begin{abstract}
Calotropis procera (Ait.) R. Br. (Family, Asclepiadaceae) commonly known as Arka is used in many ayurvedic formulations like Arkelavana and is present throughout India and in other warm, dry places such as Afghanistan, Egypt and tropical Africa. Calotropis procera is small, erect and compact shrub, which is used in several traditional medicines to cure various diseases. A study on Calotropis procera stem samples, extracted from the air-dried stem powder with different solvents such as Hexane, Chloroform, Methanol and sterile water. The standardization of stem of Calotropis procera was carried out to establish its macro and microscopical standards, physicochemical parameters and preliminary phytochemical investigation to evaluate the characters of the plant. The preliminary phytochemical analysis was done long with measurement of the leaf constants, fluorescence characteristics and extractive values. Quantitative estimation of total ash value, acid insoluble ash and water soluble ash may useful for identification of the powdered drug. The studies suggest that the observed pharmacognostic and physiochemical parameters of Calotropis procera stem are of great value in quality control and formulation development and also curing various ailments.
\end{abstract}

Keywords: Calotropis procera stem, fluorescence analysis, macroscopy, microscopy, pharmacognostic standardization, phytochemical screening.

\section{Introduction}

Calotropis procera belongs to the family Asclepiadaceae and is a soft wooded, evergreen perennial shrub. It is a xerophytic erect shrub, growing widely throughout the tropical and sub-tropical regions of Asia and Africa. This plant is popularly known because it produces large quantity of latex. Medicinal plants have no doubt remained the major sources of traditional medicine worldwide (Goyal et al, 2011). The plant, Calotropis procera (Asclepiadaceae) commonly known as Jilledachettu in Telugu and Akra in Sanskrit. The use of the plants, plant extracts, and pure compounds isolated from natural sources have always provided a foundation for modern pharmaceutical compounds. (Evans WC, 2005). Calotropis procera is a well known plant and has been traditionally used for diarrhoea, stomatic, sinus fistula, and skin disease (Alikhan et al, 2005 and Raghubir et al, 1999) and the leaf part is used to treat jaundice. There are many reports on the geographical distribution, habitat, and morphological characters of the plant. However, no work has been carried out on the stem of this plant, which contains potentially useful ethno medicinal drugs. Therefore, the present work was undertaken to study the pharmacognostic aspects of Calotropis procera stem.

\section{Plant materials}

\section{Materials and Methods}

Stem of Calotropis procera were collected from the regions in and around forest areas of Thalakona and Tirumala, Chitoor district, Andhra Pradesh, India. The plants were authenticated and certified by Dr. K. Madhava Chetty, Department of Botany, S.V.University, Tirupati. Specimens of Calotropis procera (Voucher specimen No.SVUT/CP/17) were conserved in S.V. University herbarium, Tirupathi. The stem powder and the extracts of the powder in different solvents were examined under ordinary day light and in UV- light $(254 \mathrm{~nm}$, $365 \mathrm{~nm}$ ). The fluorescence was determined according to the methods of Chase and Pratt (Chase et al, 1949). The total ash, water-soluble ash and acid-insoluble ash content was determined by employing standard methods of analysis as described in the Indian Pharmacopoeia (Anonymous 1996). Quantitative determinations of the powdered drug like physicochemical constants (Corner, 1976) fluorescence (Brindha et al, 1981) and a preliminary phytochemical screening were carried out.

\section{Method for Microscopical observation}

Hand section of various parts was taken, stained and mounted following usual micro techniques. Micro chemical tests for cell wall and cell contents were performed according to Johansen (1940). Representative photographs were also taken with the help of inverted microscope for photo documentation (Leitz, Japan). 


\section{Method for Powder microscopy}

The powder characteristics of Calotropis procera (stem) were studied according to standard methods. Separate slides are prepared for observation of lignified tissues (phloroglucinol + Hydrochloric acid), starch (iodine solution) and non-lignified characters. About $500 \mathrm{mg}$ of the sample is taken and mixed thoroughly with water in a watch glass. Warmed, cleared in chloral hydrate and washed thoroughly in water. Stained with phloroglucinol and concentrated hydrochloric acid. It is then washed thoroughly in water. Stained with dilute iodine solution and again washed thoroughly in water. A drop of each of the above is mounted in glycerine and observed for different characteristic features.

\section{Morphological characteristics of stem}

Calotropis is a large, bushy shrub with decussate, obovate, coriaceous, auriculate, leaves with acute, subsessile apices extraaxillary, umbellate, panicale inflorescene with purple corolla and erect lobes. The morphological studies revealed the leaves to be subsessile, $6-15 \mathrm{~cm}$ by $4.5-8 \mathrm{~cm}$, broadly ovate, ovate-oblong, elliptical, or obovate, acute, pubescent when young and glabrous on both sides on maturity.

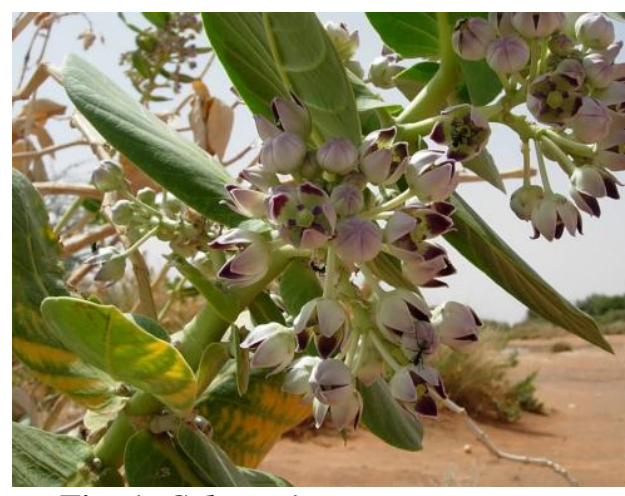

Fig: 1. Calotropis procera

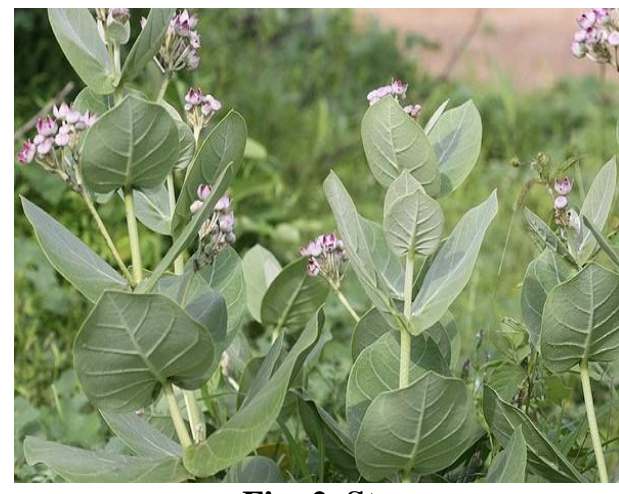

Fig: 2. Stem

\section{Microscopy of Calotropis procera stem}

Epidermis is an outermost layer of uniseriate cells with thick cuticle. Uni- and multicellular hairs clothe epidermis almost completely. Cells are barrel to rectangular and are compactly arranged. Cortex forms a few layers below the epidermis which are collenchymatous (thickened corners). A few chloroplasts may also occur in these cells. Rest of the cortex is parenchymatous. Intercellular spaces are numerous. Endodermis layer of uniseriate cells forms a wavy ring around the vascular tissue. The cells are barrel-rectangular shaped and are compactly arranged. Characteristic casparian thickening is lacking. It, however, contains starch grains. Pericycle is in the form of small patches of sclerenchymatous fibres. A few parenchymatous cells of the original pericycle are present between these groups.

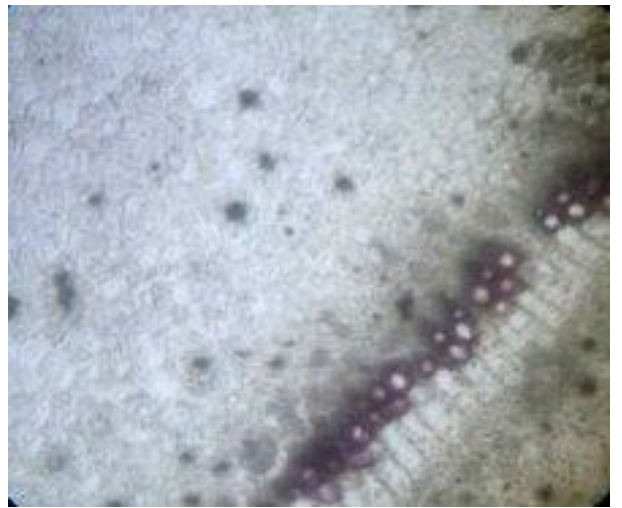

Fig: 3. Microscopy of Calotropis procera stem

The present study highlights the results of a comprehensive study on the microscopic parameters including the gross anatomical features, leaf constants, cellular composition and cellular inclusion of the stem. The powder contains fibres, cork, lignified reticulate vessels, Trichomes and Mesophyll (Fig: 4). 


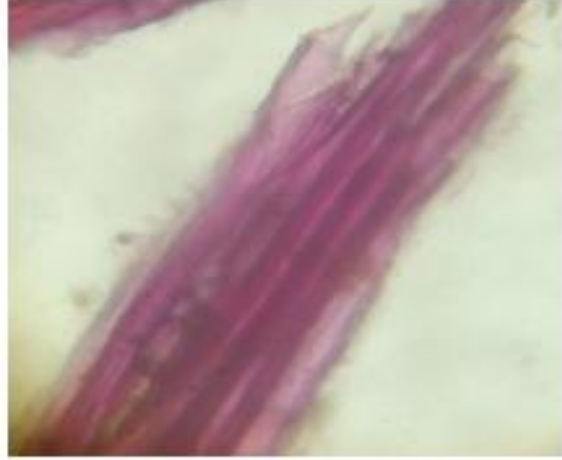

Fibres

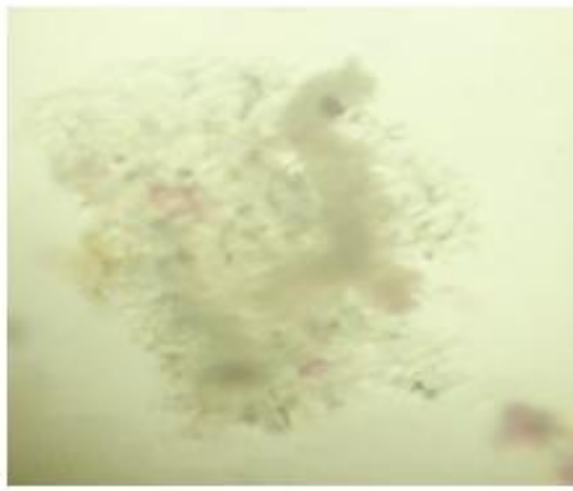

Cork cells

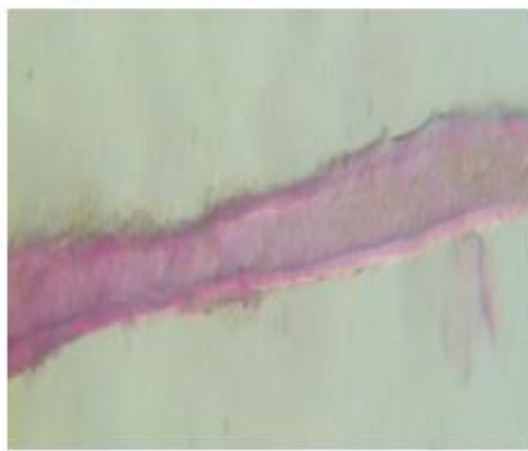

Vessels

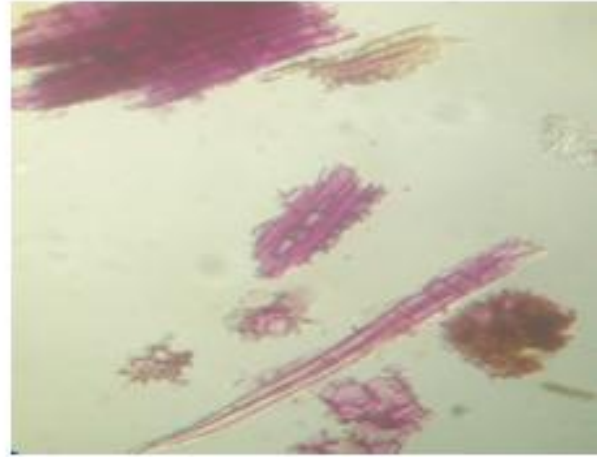

Vessels

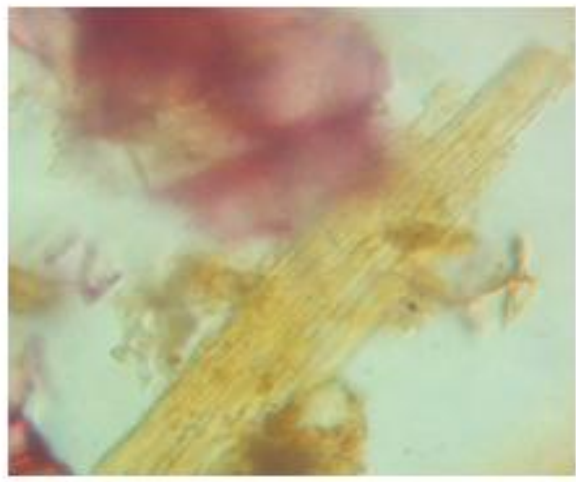

Mesophyll

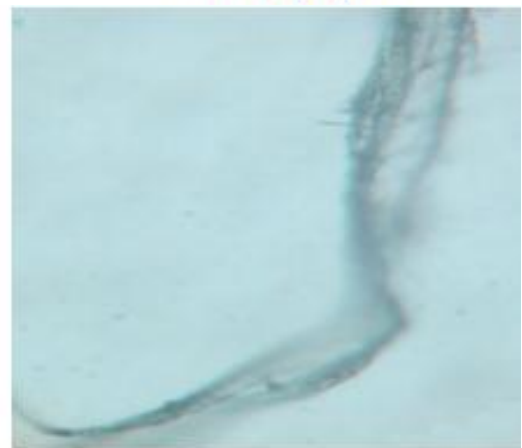

Trichomes

Fig: 4. Powder Microscopy of Calotropis procera stem

The results of the quantitative and qualitative analysis of the stem samples are depicted in Tables: 1-4.

Table: 1. Leaf Constants of Calotropis procera stem

\begin{tabular}{|c|c|}
\hline Leaf Constant & \\
\hline Stomatal Number & 10.9 \\
\hline Stomatal index & 43.2 \\
\hline Vein-islet Number & 25.1 \\
\hline Veinlet termination Number & 18.9 \\
\hline Palisade ratio & 14.6 \\
\hline
\end{tabular}


Table: 2. Ash value of powdered stem of Calotropis procera

\begin{tabular}{|c|c|}
\hline Type of ash & Ash value (\%) \\
\hline Total ash & 18.2 \\
\hline Acid insoluble ash & 1.5 \\
\hline Water soluble ash & 1.7 \\
\hline Sulphated ash & 2.08 \\
\hline
\end{tabular}

Table: 3. Fluorescence of Calotropis procera stem powder in different solvents

\begin{tabular}{|l|l|l|l|}
\hline \multirow{2}{*}{ Treatment } & \multirow{2}{*}{ Normal Light } & \multicolumn{2}{|c|}{ Under UV Light } \\
\cline { 3 - 4 } & & $\mathbf{2 5 4} \mathbf{~ n m}$ & $\mathbf{3 6 5} \mathbf{~ n m}$ \\
\hline Dry Powder & Brown & Green & Green \\
\hline Powder + Dil. $\mathrm{HCl}$ & Pale Brown & Light Green & Brown \\
\hline Powder + Conc. $\mathrm{HCl}$ & Pale Brown & Light Green & Dark Brown \\
\hline Powder + Dil. $\mathrm{H}_{2} \mathrm{SO}_{4}$ & Brown & Green & Black \\
\hline Powder + Conc. $\mathrm{H}_{2} \mathrm{SO}_{4}$ & Light Brown & Green & Black \\
\hline Powder + Dil. $\mathrm{HNO}_{3}$ & Dark Green & Black & Black \\
\hline Powder + Conc. $\mathrm{HNO}_{3}$ & Dark Green & Black & Black \\
\hline Powder+Dil. Ammonia & Pink & Violet & Brown \\
\hline Powder+1N NaOH in water & Green & Green & Brown \\
\hline Powder+Ferric Chloride & Greenish Brown & Black & Black \\
\hline Powder+Iodine Solution & Brown & Brown & Black \\
\hline Powder+Bromine water & Yellowish Brown & Yellowish Brown & Yellowish Brown \\
\hline
\end{tabular}

Table: 4. Preliminary phytochemical screening of stem powder of Calotropis procera:

Phytochemical Screening was carried out using standard methods to detect the bioactive compounds like alkaloids, tannins, phenols, steroids, flavonoids, saponins (Trease et al, 1989).

\begin{tabular}{|c|l|c|c|c|c|}
\hline \multirow{2}{*}{ S. No } & \multicolumn{1}{|c|}{ Group of phytoconstituent } & \multicolumn{4}{c|}{ Extract } \\
\cline { 3 - 6 } & Hexane & Chloroform & Methanolic & Aqueous \\
\hline 1 & Carbohydrates & - & - & + & - \\
\hline 2 & Gums and mucilage & - & + & + & - \\
\hline 5 & Fats and oils & - & - & + & - \\
\hline 6 & Alkaloids & - & - & + & - \\
\hline 7 & Triterpenoids & - & + & + & - \\
\hline 8 & Steroids & + & - & + & - \\
\hline 9 & Flavonoids & - & + & + & - \\
\hline 10 & Glycosides & + & + & + & + \\
\hline 11 & Saponins & - & + & + & + \\
\hline 12 & Tannins and phenolic compounds & + & - & & + \\
\hline 13 & Coumarins & - & + & + & + \\
\hline 14 & Proteins and amino acids & - & + & + & + \\
\hline
\end{tabular}

(+) indicates presence

(-) indicate absence

The extracts from different parts of the plant have significant therapeutic value. The leaves are used to treat joint pain and reduce swelling. It is also used as a homeopathic medicine (Meena et al, 2011). Murti et al, (2010) analysed Pharmacognostic standardization of leaves of Calotropis procera. Phytochemical and antimicrobial evaluation has been carried out on other species of Calotropis. Varahalarao et al, (2010) examined bioassays for antimicrobial activities using stem, leaves and flowers of Calotropis procera. Shrivastava et al, (2013) Phytochemical Investigation of Different Plant Parts of Calotropis procera.

\section{Discussion}

By virtue of their photosynthetic machinery, stems serve as a sink for several metabolites and as an important source of several bioactive compounds. The macroscopic and microscopic evaluation of stem of Calotropis procera, the quantitative estimation of leaf constants, ash values, and fluorescence, and preliminary phytochemical screening of the stem powder would be of considerable use in the identification of this drug. 
Empirical knowledge about medicinal plants plays a vital role in primary health care and has great potential for the discovery of new herbal drugs. These findings may be useful to supplement existing information with regard to the identification and standardization of Calotropis procera, even in the powdered form of the plant drug, to distinguish it from substitutes and adulterants. These studies also suggested that the observed pharmacognostic and physicochemical parameters are of great value in quality control and formulation development. In conclusion, the present study may be useful to supplement information with regard to its identification and standardization, and in carrying out further research and revalidation of its use in the Ayurvedic System of Medicine.

\section{Acknowledgments}

The authors are thankful to University Grants Commission (UGC), New Delhi, India for funding.

Konathala Rajesh is a Junior Research Fellow (Major Research Project) of the University grants Commission, New Delhi, India.

\section{References}

[1]. Goyal, M. and Mathur, R. Antimicrobial potential and Phytochemical analysis of plant extracts of Calotropis procera. Int.J.of DrugDiscovery and Herbal Research, 2011; 1(3):138-143.

[2]. Evans WC. Trease and Evans Pharmacognosy. Saunders an Imprint of Elsevier; 2005; 41-7.

[3]. Alikhan I, Khanum A. Medicinal and Aromatic Plants of India. Ukaaz Publication; 2005; 133-134.

[4]. Raghubir R, Rasik M, Gupta AJ. Healing potential of Calotropis procera on dermal wounds in guinea pigs. J Ethnopharmacol. 1999; 68:261-266.

[5]. Chase CR, Pratt R. Fluorescence of powdered vegetable drugs with particular reference to development of a system of identification. Am Pharm Assoc. 1949; 38:324-331.

[6]. Anonymous, The Indian Pharmacopoeia. New Delhi: Govt. of India Publication; 1996.

[7]. Corner EJH. The Seeds of Dicotyledons. London: Cambridge University Press; 1976.

[8]. Brindha P, Sasikala P, Purushothamam KK. Bull Med Ethno Bot Res. 1981; 3:84-86.

[9]. Trease, G. E. and Evans, W. C. A Textbook of Pharmacognosy. Bacilliere tinal Ltd., London, 13th edition; 1989.

[10]. Meena, A. k., Yadav, A. and Rao, M. M. Ayurvedic uses and pharmacological activities of Calotropis procera Linn. Asian J. of traditional Medicines, 2011; 6(2): 45-53.

[11]. Murti, Y., Yogi, B. and Pathak, D. Pharmacognostic standardization of leaves of Calotropis procera (Ait.) R.Br. (Asclepiadaceae). Int. J. Ayurveda Res, 2010; 1:14-7.

[12]. Varahalarao, V. And Chandrashekhar, N. In vitro bioactivity of Indian medicinal plant Calotropis procera. J. of global Pharma technology, 2010; 2(2):43-45.

[13]. Shrivastava, A., Suchita Singh, Sanchita Singh. Phytochemical Investigation of Different Plant Parts of Calotropis procera. International Journal of Scientific and Research Publications, 2013; 3(8):1-4. 